\title{
Repair of Cracks on Concrete Structures
}

\author{
Agu Ransford Tetteh ${ }^{1}$, Ye Liang ${ }^{2}$ \\ ${ }^{12}$ School of Civil Engineering and Architecture, Zhejiang University of Science and Technology, Hangzhou 310023, China
}

\begin{abstract}
Cracks in concrete structures have many causes. They can affect the appearance or indicate significant structural loads or lack of durability. Cracks can represent the full extent of the damage or indicate serious problems. Its importance depends on the type of structure and the type of cracking. For example, cracks that are acceptable for buildings may not be acceptable for water retention structures. Correct crack repair depends on knowledge of the causes and selection of repair procedures that take these causes into account. Otherwise, the repair can only be temporary. Cracks are a typical defect that are unavoidable in concrete. If cracks exceed the allowable widths defined in the codes of practice, they considerably reduce the strength, stiffness and durability of the concrete structure and therefore need to be repaired. However, many components are often needed, such as reinforced concrete structures need repair to restore structural integrity and protect the reinforcement Weather conditions. Different types of materials and methods are available. Repair of protruding cracks in concrete structures. In this paper, causes of cracks, repair materials and the repair method are been discussed. Successful long-term repair procedures must attack the causes of the cracks as well as the cracks themselves.
\end{abstract}

\section{Keywords: Concrete Structures, Causes of Crack, Repair Material, Repair Method Description}

\section{Introduction}

Concrete structures are the most commonly used building material due to their good durability, which has been used to build a large number of constructions from houses to bridges for many years. As a result, concrete structures that are well designed and made of high-quality materials generally require little maintenance or repair unless exposed to particularly aggressive conditions. In the 1960 s, there was a phase of dynamic growth for the chronic homeless [1]. The widespread belief that concrete is a sustainable and maintenance-free building material has changed in recent years. Several examples can be shown where the concrete did not work as expected [2]. While hundreds of thousands of successful reinforced concrete structures are built around the world each year, there are a large number of reinforced concrete structures that deteriorate or become insecure due to inadequate construction design details, build quality and maintenance, chemical attack, overload, rebar corrosion and foundations settlement, deposit, wear, fatigue effect, atmospheric effects, abnormal flooding [3], changes in use, changes in configuration and natural disasters, etc. All these factors affect the durability of concrete structures [4]. In recent years, the growing need for maintenance and repair of structures has led to major deviations. Investments in maintenance and repair work on old structures in Europe (and particularly in Italy) are estimated to account for around $50 \%$ of total construction expenditure. Therefore, restoration costs have nearly doubled compared to the past decade, when it was between 25 and $30 \%$. Some estimates showed that maintenance and repair costs in 2010 represented about $85 \%$ of total construction expenditure.

In the same year, $\$ 50$ billion will be spent on repairing worn bridges and viaducts [5]. The repair of worn concrete structures is important not only for use during the expected useful life, but also to ensure the safety and maintenance of their components so that they meet the same requirements as those built today and in the future [6] Suitable Repair of these structures improves function and performance, restores and increases strength and rigidity, improves the appearance of the concrete surface, guarantees waterproofing, prevents the development of a corrosive environment during reinforcement and improves durability. Of course, both ecologically and economically, restoration methods are preferable to replacement structures. One of the current interests in the field of repair is concrete structures due to load conditions.

Concrete was recently the most important material in the construction industry for a large volume of modern works. It is used on roads, sidewalks, bridges and tall buildings. It is generally believed that civil engineers will break concrete. Due to its nature and composition, concrete is a brittle material. Therefore, concrete has a relatively low tensile strength and is also subject to volume stability. Despite its long history of use, our understanding of the material has only recently been developed, especially with regard to durability. It is generally accepted that concrete is a durable material and maintenance-free construction. This concept has recently been changed. Many studies have shown that concrete does not perform as expected due to a number of factors that contribute to concrete structures or cause cracks. The causes of cracks, materials and repair methods are briefly described in this section.

\section{Causes of Cracks on Concrete}

Cracks are the most common phenomenon of deterioration of concrete. Cracks in concrete may occur in both the plastic state (Figure 1 and figure 2) as well as hardened state owing to the internal stresses that arise from the response of the constituent's materials to the external mechanism, such as thermal expansion, overloading, restraint, and chemical reactions as well as their environment ${ }^{[7]}$. Cracks arise in the cured state due to design errors (incorrect understanding of the structural effect, insufficient detail, errors in design calculation);

Design errors (incorrect positioning of the steel, insufficient reinforcement, incorrectly made construction joints, poor compaction, segregation, poor hardening, excessive water content); the load on the structure beyond the design load, due to changes in use, unexpected accidents such as explosions, blows and accidental effects of fire [8,9]. The ACI 224 [7] committee also reported that cracks in hardened

Volume 9 Issue 4, April 2020 


\section{International Journal of Science and Research (IJSR) \\ ISSN: 2319-7064}

ResearchGate Impact Factor (2018): 0.28 | SJIF (2019): 7.583

concrete may occur due to chemical reactions, reinforcement, wear and corrosion, poor construction practices, construction overload, construction defects and details. [10] You have described the causes of the main external physical and mechanical factors that cause the decomposition and failure of concrete structures. These are restraint against movement, abrasion, wetting and drying, freezing and thawing, overloading, structural alteration, fire resistance and settlement.

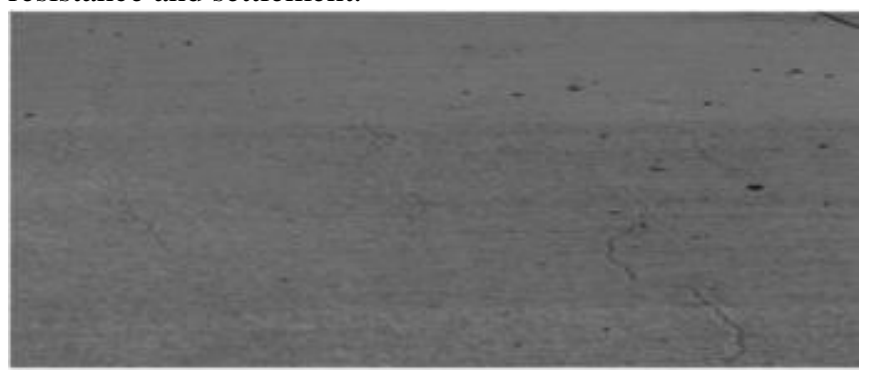

Figure 1: Plastic shrinkage in a Bridge deck

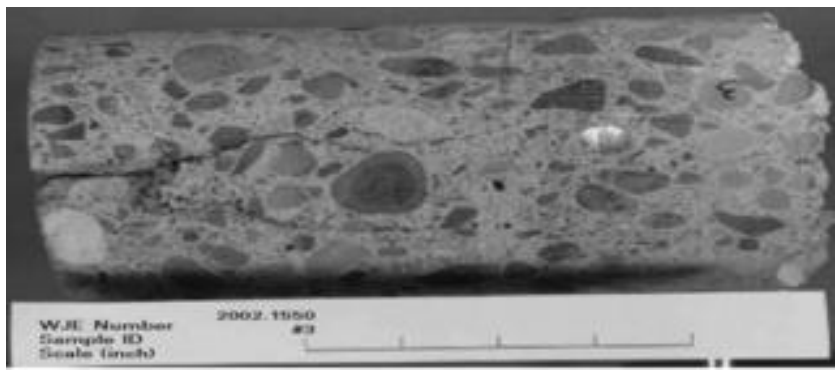

Figure 2: Bridge deck with plastic shrinkage cracking

\section{Concrete Repair Materials}

The International Concrete Repair Institute (ICRI) was established to improve the duration of concrete repairs and increase value for builders. Concrete repair materials can be formulated to provide a variety of properties because properties affect the performance of repairs. Choosing the right material requires careful research. A repair material is of value only if it enables a technical product for a concrete structure to fulfill its intended function [11]. Lately, the sustainability problem of the repaired structures has been the biggest problem. Repair materials should have properties resistant to bad weather, chemical attack, wear or any other spoilage process. Durable concrete retains its original shape, quality and suitability for use when exposed to its environment [12]. [13] describe the selection process for the permanent repair of reinforced concrete structures. The choice of suitable repair materials was based on the intrinsic properties and on the compatibility between the repair material and existing concrete substrates [14]. [15] [16] [17] [8] discussed the different types of repair materials that have recently been used for successful renovations. Consequently materials in cement-based materials (ordinary portland cement mortar, shrink-free mortar, ordinary cement mortar, shrinkage compensation mortar, hand-applied concrete, projection concrete or projection concrete and free-flowing micro-concrete), polymer mortar materials (light / medium modified polymer mortar, modified high strength polymer mortar mortar).
Polymer concrete based materials (polymer concrete and Portland cement concrete, polymer-impregnated concrete), polymer-based organic materials (epoxy resins, polyurethanes, polyester resins, styrene, butadiene), composite materials (fiber-reinforced polymer, polymer composites reinforced with powder fibers).

Cement mortars, polymer resins and emulsions, acrylic resins, polymer modified cement mortars, non-passivating and passivating epoxy resin are available for priming concrete substrates and reinforcing bars.

\subsection{Crack Repair Methods}

This several methodologies have been shown to be feasible for repairing of existing cracked and following the evaluation of the concrete crack structures, a suitable repair procedure can be selected. Successful repair procedures take into account the cause(s) of the cracking. For example, if the crack is mainly due to the reduction of drying, the cracks are likely to stabilize over time. On the other hand, if the cracks are due to the continuous deposition of the base, the repair is useful only if the problem of the deposition is solved. This section provides methods for repairing cracks in concrete structures, including a summary of the properties of cracks that can be repaired by each method, the types of structures repaired, and a description of the methods used.

\subsection{Externally applied loads}

It is known that the load-related tensile stresses lead to cracks in the concrete elements. This point is easily recognized and accepted in the construction of reinforced concrete structures. Current construction methods (ACI 318 and the AASHTO standard specification for road bridges) use reinforcing steel not only to withstand stress forces but also to ensure an adequate distribution of cracks and a reasonable width limit of the cracks. Experimental evidence forms the basis for the following general conclusions about the variables that control cracks in curved parts: the width of the crack increases with increasing stress of the steel, the thickness of the surface layer and the surface of the concrete surrounding each harness. Steel stress is the most important variable. The diameter of the bar does not play an important role. The width of a crack in the floor increases as the deformation gradient between the steel and the stress area of the beam increases. The equation often used to predict the maximum surface crack width when the curvature was developed by [41].

A simplified version of this equation is:

$$
w=0.076 \beta f_{s} \sqrt[3]{d_{c} A} \times 10^{3}
$$

where :

$w=$ most probable maximum crack width, in. $(\mathrm{mm})$;

$\beta=$ ratio of distance between neutral axis and tension face to distance between neutral axis and centroid of reinforcing steel (taken as approximately 1.20 for typical beams in buildings);

$f_{s}=$ reinforcing steel stress, $k s i(M P a)$;

$d c=$ thickness of cover from tension fiber to center of the closest bar, in. (mm); and

Volume 9 Issue 4, April 2020 


\section{International Journal of Science and Research (IJSR) \\ ISSN: 2319-7064}

ResearchGate Impact Factor (2018): 0.28 | SJIF (2019): 7.583

$A=$ area of concrete symmetric with reinforcing steel divided by number of bars, in. ${ }^{2}\left(\mathrm{~mm}^{2}\right)$.

A change from this equation is used in the specifications of the AASHTO bridge, which effectively limits the width of the slots to 0.015 or 0.012 inches $(0.38$ or $0.30 \mathrm{~mm})$ depending on the lighting conditions.

A range of crack width equations have been developed for pre stressed concrete elements [7], but no method has been widely accepted.

The maximum width of the cracks in the tensile members is greater than that provided in the expression for the flexure members [40]. The absence of a deformation gradient and compression zone in the tensile members is the likely cause of the larger crack widths. Based on limited data, the following expression has been proposed to estimate the maximum indirect stress of the crack width [7].

$$
w=0.10 f_{\sigma} \sqrt[3]{d_{c} A} \times 10^{-3}(i n,-I b)
$$

Additional information on cracking of concrete in direct tension is provided in ACI 224.2R. Flexural and tensile crack widths can be expected to increase with time for members subjected to either sustained or repetitive loading. Although a large degree of scatter is evident in the avail-able data, a doubling of crack width with time can be expected [43]; [44]; [42]; [46]; [45].

\subsection{Epoxy Injection}

Epoxy is an adhesive whose application is an inexpensive and effective method of repairing immobile cracks in concrete walls, slabs, columns and columns with a crack width of only $0.05 \mathrm{~mm}(0.002 \mathrm{inch})$ and a height of $6 \mathrm{~mm}$ (0.002 inch) is epoxy by injection. The technique generally consists of narrow access and ventilation spaces along the cracks, sealing the crack on exposed surfaces and injecting the epoxy under pressure. Epoxy injection has been successfully used to repair cracks in buildings, bridges, dams and other types of concrete structures [19]. However, if the cause of the cracking is not resolved, it will likely return close to the original cracking. If the cause of the cracks cannot be removed, two options are available. One is to grind and seal the crack and treat it as a compound. The second is to make a compound that absorbs movement and then injects the crack with epoxy resin or other suitable material. The epoxy materials used for structural repairs must comply with [20]. [19] Describes methods of sealing joints, including joint design, available materials and application methods.

With the exception of some moisture-resistant epoxies, this technique cannot be used if the cracks are actively licked and cannot be dried. Wet cracks can be injected with moistureresistant materials, but crack contaminants (including sludge and water) can reduce the effectiveness of epoxy to repair structural cracks. The use of a low modulus flexible adhesive in a crack does not allow significant movement of the concrete structure. The effective modulus of elasticity of a flexible adhesive in a crack is essentially the same as that of a rigid adhesive [21] because the surrounding concrete has a thin material layer and a high lateral bond. Epoxy injection requires a high level of skill to function satisfactorily and the use of this technique can be limited by the ambient temperature. The general procedures for epoxy injection are as follows [19].

Clean the cracks: Firstly, clean the cracks that have been contaminated, to the extent that this is possibly practical. Impurities such as dirt, grease, dirt or fine concrete particles that prevent epoxy from penetrating and adhering are evident for the effectiveness of repairs. Contaminants must be removed by vacuuming or rinsing with water or other particularly effective cleaning solutions. The solution is rinsed with compressed air and a neutralizing agent or sufficient time to air dry is provided. It is important to recognize the practical limitations of full crack cleaning. Adequate assessment of the magnitude and necessity of cleaning should be made. Test cleaning may be required.

Seal the surfaces: Cracks in the surface must be sealed to prevent epoxy leakage before gelling. If the crack surface cannot be reached, but a filler is present or if a plate is being repaired, the filler or carrier material is sometimes a sufficient seal. However, this condition can rarely be diagnosed in advance, and an uncontrolled injection can cause damage, such as blockage of a drainage system. Therefore, extreme caution is recommended when injecting cracks that are not visible on all surfaces. A surface can be sealed by applying an epoxy resin, polyester or other sealing material suitable for the surface of the crack and allowing it to cure. If a permanent glossy appearance through the crack is questionable and high injection pressure is not required, a removable plastic surface seal can be applied along the crack surface. At the end of work, the sealant can be removed to reveal the non-glossy surface. Concrete seals can also be used when the appearance of the job is important. If extremely high injection pressures are required, the crack in a V-shape filled with epoxy resin can be cut to a depth of 13 $\mathrm{mm}(1 / 2 \mathrm{inch})$ and a width of $20 \mathrm{~mm}(3 / 4 \mathrm{inch})$ the surface.

Install the entry and venting ports: Typical settings for entry and venting ports are shown in Fig. 3. Three methods are in general use:

- Fittings inserted into drilled holes - This method was the first to be recognized and is often used in combination with crepe $\mathrm{V}$ grooves. The procedure involves making a hole in the crack, about $3 / 4$ inch. $(20 \mathrm{~mm})$ in diameter and $1 / 2-1$ in. (13-25 mm) below the tip of the V-groove section where an accessory such as a pipe stem or a tire valve stem is glued with an epoxy adhesive. A spindle and a vacuum drill or a water-cooled core drill are useful to prevent cracks from becoming clogged with drill dust.

- Bonded flush fitting - When the cracks are not Vgrooved, a method mostly used to provide an entry port is to bond a fitting flush with the concrete face over the crack. The flush fitting has an opening at the top for the adhesive to enter and a flange at the bottom that is bonded to the concrete 


\section{International Journal of Science and Research (IJSR) \\ ISSN: 2319-7064}

ResearchGate Impact Factor (2018): 0.28 | SJIF (2019): 7.583

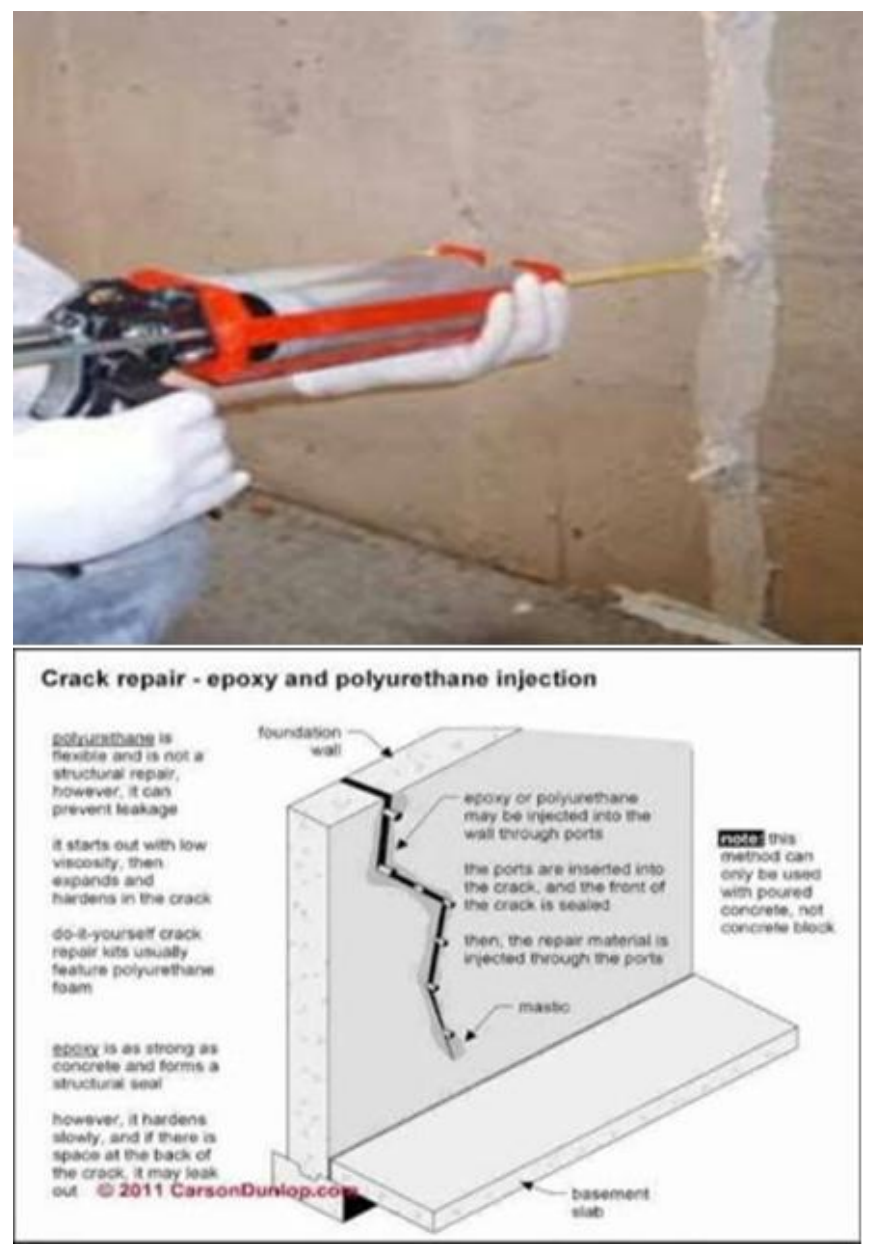

Figure 3: Epoxy injection through the ports shown (FDOT)

- Interruption in seal - Another way to provide input is to leave the seal out of the slot. This method can be used if special sealing devices are available that cover the unsealed part of the crack and can inject the adhesive directly into the crack without leaking.

Mix the epoxy: This is done either by batch or continuous methods. In batch mixing, the adhesive components are premixed according to the manufacturer's instructions, usually using a mechanical stirrer such as a paint mixing paddle. Care should be taken to mix only the amount of glue that can be used before the material starts to gel. As the adhesive material begins to gel, the flow properties begin to change and the pressure injection becomes more and more difficult. In the continuous mixing system, the two liquid adhesive components pass through the measurement and direct the pumps before passing through an automatic mixing head. The continuous mixing system allows the use of fast-curing adhesives with a short duration.

Inject the epoxy: Hydraulic pumps, paint pressure pots, or air-actuated caulking guns may be used. The pressure for injection must be carefully selected. Increasing pressure often does little to speed up the injection rate. Using excessive pressure can propagate existing cracks, which can cause additional damage. If the crack is vertical or oblique, the injection process should begin by pumping epoxy resin into the entrance door to the lowest level until the epoxy level reaches the entrance door above it. The lower injection port is then closed and the process repeated until the crack is completely filled and all the ports are closed. For horizontal cracks, the injection should be done from one end to the other in the same way. The crack is full if the pressure can be maintained. If the pressure cannot be maintained, the epoxy will continue to flow into the blank areas or leave the crack.

Remove the seal from the surface: After the injected epoxy resin has cured, the seal must be removed from the surface by sanding or other suitable means.

\begin{abstract}
Alternative method: For massive structures, an alternative method is to drill a series of holes [usually 20-100 mm in diameter] that catch the crack in several places. The holes are generally $1.5 \mathrm{~m}$ apart. Another recently used method is a vacuum or vacuum support method.
\end{abstract}

There are two techniques: One is to completely enclose the broken object with a bag and place the liquid glue in the bottom part and create a vacuum in the top part. The other technique is to inject the cracks on one side and suck on the other.

Epoxies are used; Acrylic and polyester have proven their worth. [22] Describe the use of epoxy injection as an effective medium-term repair method for laminated bridges. The method can also be tested for other applications and is available as an option, but is generally not accepted. Successful repair depends on the absence of contaminants with anti-tear inhibitors. Epoxy resins and injection methods should be carefully selected when injecting delamination. If the surrounding concrete is not deep enough or insufficiently anchored, the injection process may fail or increase the degree of delamination. [23] Provides information on bridges observed up to seven years after the injection. [24] Describe epoxy injection as a method of reconnecting the layers of the delaminated bridge.

\subsection{Routing and sealing}

Cracks can be placed and sealed under conditions that need to be repaired and do not require structural repairs. In this method, the crack is enlarged along the exposed surface and filled and sealed with a suitable joint sealant. This is a common cracking treatment method and is relatively straightforward compared to the procedures and training required for epoxy injection. The method is best suited for relatively flat horizontal surfaces such as floors and corridors. Milling and sealing can, however, be performed on vertical surfaces with a non-sinking sealant and on curved surfaces (pipes, stacks and rods). Milling and sealing are used to treat both fine patterned cracks and larger, more insulated cracks. A common and effective application is sealing by sealing cracks in the concrete surface in the presence of water or when hydrostatic pressure is applied. This treatment reduces the ability of moisture to reach or penetrate the reinforcing steel, causing surface stains or other problems. 


\section{International Journal of Science and Research (IJSR) \\ ISSN: 2319-7064}

ResearchGate Impact Factor (2018): 0.28 | SJIF (2019): 7.583

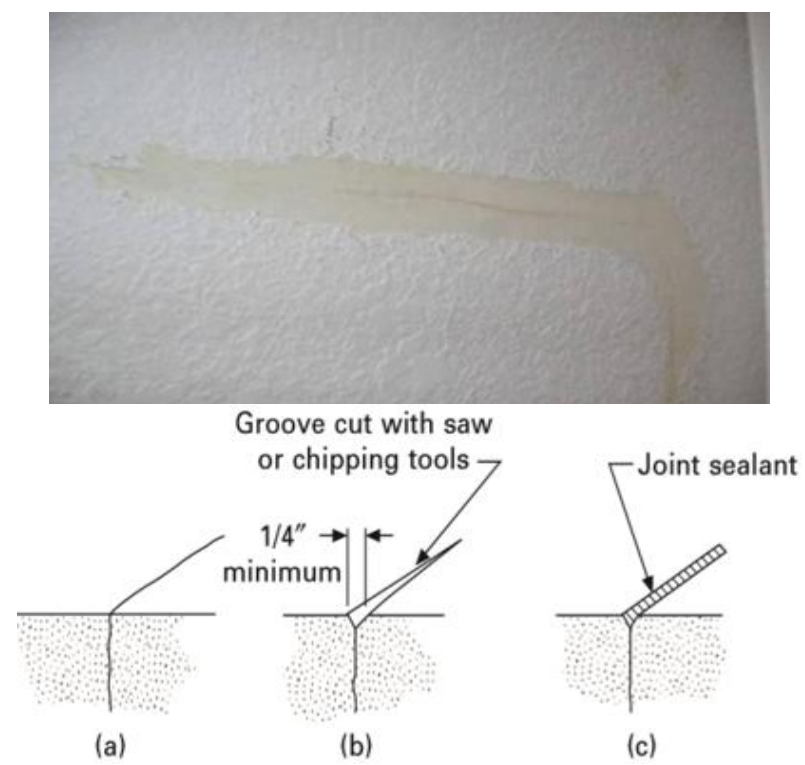

Figure 4: Repair of crack by sealing (a) Original crack; (b) routing (c) sealing ${ }^{[18]}$

Sealants can be made from a variety of materials, including epoxies, urethanes, silicones, polysulfides, asphalt materials, or polymer mortars. Cement mortar should be avoided because of the risk of cracking. For floors, the kit must be rigid enough to withstand expected traffic. Satisfactory sealants must withstand cyclic deformation and must not be brittle. The procedure involves preparing a groove on the surface, with a typical depth between 6 and $25 \mathrm{~mm}$. You can use a concrete saw, hand tool or pneumatic tool. The groove is cleaned and dried with an air jet, sand jet or water jet. A sealant is inserted into the dry groove and allowed to cure. A liability switch can be fitted to the bottom of the slot so that the bottom sealant can change without stress concentration (Figure 5). The adhesion switch can be a strip or a polyethylene tape that does not adhere to the sealant. Particular attention is needed when detailing the joint, so that the width-to-depth ratios take into account the expected movement [19].

In some cases the top band (tape coating) is used independently or in combination with milling and sealing. This method is used to improve edge chipping protection and to achieve a more uniform appearance for aesthetic reasons. A typical bridging method is to prepare a range of about 25 to $75 \mathrm{~mm}$ (1 to 3 inches) on each side of the crack by sandblasting or other surface preparation agents and a coating (eg urethane) of 0.0408 inches $(1-2 \mathrm{~mm})$ thick in a band above the crack. Before binding in areas that are not restricted to traffic, a junction switch is sometimes used on a crack that has not been placed or on a crack that has been previously placed and sealed. Cracks subject to minimal movement can be misused (Figure 6.) However, if significant movement can occur, milling and sealing should be used in conjunction with the top belts to ensure accurate repair. For example, when sealing liners and sewer basins exposed to low groundwater pressure, the crack must be guided to create a joint area (slot) that complies with the requirements for width and shape factor of a joint having equivalent movement.

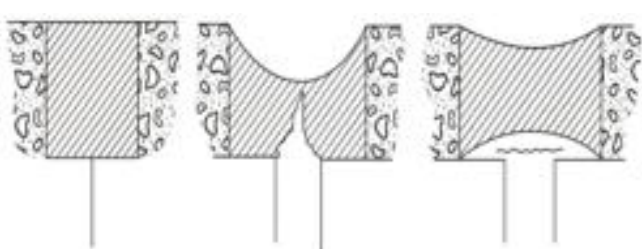

(a) Crock closed (b) No bond breaker (c) With bond breakes

Figure 5: Effect of bond breaking ${ }^{[7]}$

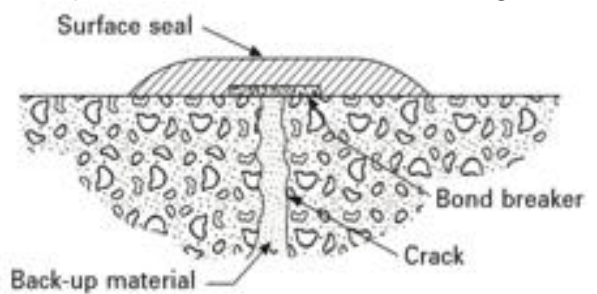

Figure 6: Surface sealing for cracks subject to movement ${ }^{[7]}$

To maintain hydraulic efficiency in some structures, it may be necessary to cut the concrete surface near the crack and position the sealing plug flush with the original streamlines. Therefore, the crack should be cleaned with a sandblast, air and water. The putty is inserted into the guided tear slot and a retention cap is placed over the putty to limit it (Figure 7.). A simple support can be made by placing a metal strip over the crack and attaching it to extendable anchors or bundled screws installed into the concrete along one side of the crack.

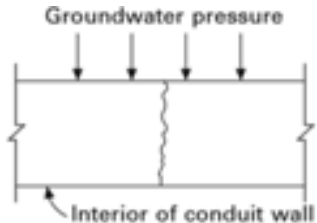

(a)

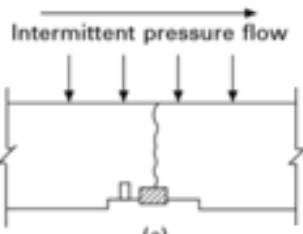

(c)

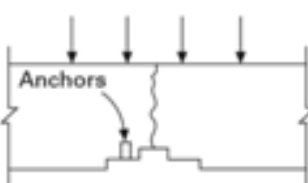

(b)

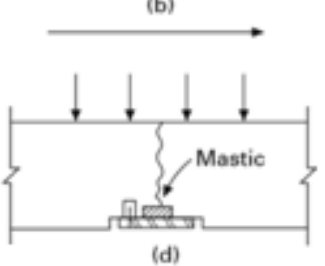

(d)
Figure 7: Repair of cracks with a backing plate to hold the putty in place against pressure: (a) crack in the pipe wall; (b) cut for sheet and putty: install expandable anchors; (c) filling with putty; (d) Hold the support plate on one side only to allow movement [7].

\subsection{Stitching}

During sewing, the holes on either side of the tear are drilled and grouped into metal U-shaped units with short legs (staples or stitches) covering the tear [18], as shown in (Figure 8). The seam is used when it is necessary to restore tensile strength in large cracks [25]. Sewing a crack tends to stiffen the structure, and the reinforcement can increase the overall structural limitation, causing the concrete to break elsewhere. Therefore, it may be necessary to reinforce adjacent sections with appropriate reinforcement methods. Since stresses are often concentrated, it may be necessary to use this method in combination with other methods. The sewing process includes drilling holes on both sides of the tear, cleaning the holes, and anchoring the staple legs in the holes with an anti-shrink mortar or epoxy-based adhesive

Volume 9 Issue 4, April 2020 www.ijsr.net 


\section{International Journal of Science and Research (IJSR) \\ ISSN: 2319-7064}

ResearchGate Impact Factor (2018): 0.28 | SJIF (2019): 7.583

system. The clips must have length, orientation, or both variables, and must be arranged so that the stress transmitted by the fracture is not applied to a single level within the section, but is distributed over an area.
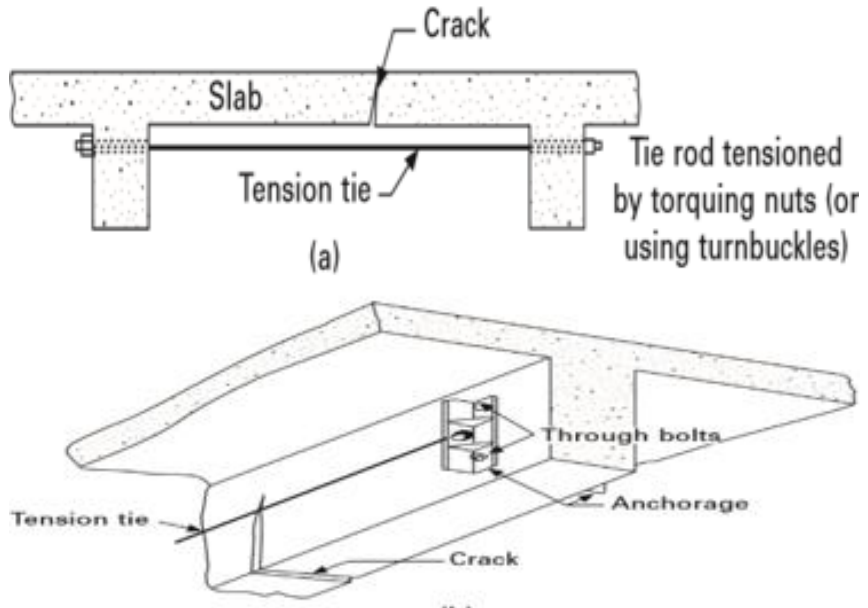

(b)

Figure 10 a: Examples of external prestressing: (a) to correct cracking of slab; (b) to correct cracking of beam ${ }^{[18]}$

Fill the hole and break with epoxy injection and place a reinforcing bar in the drilled hole. Usually 4 or 5 bars $(10 \mathrm{~m}$ or $15 \mathrm{~m}$ ) are used that extend at least $0.5 \mathrm{~m}$ on each side of the crack. Reinforcing bars can be spaced depending on repair needs. They can be placed in any desired model, depending on the design criteria and the position of the existing reinforcement. The epoxy resin connects the rod to the walls of the hole, fills the crack surface, reconnects the lean concrete surfaces in monolithic form, thus strengthening the section. The epoxy used to reconnect the crack must have a very low viscosity and must meet [20].
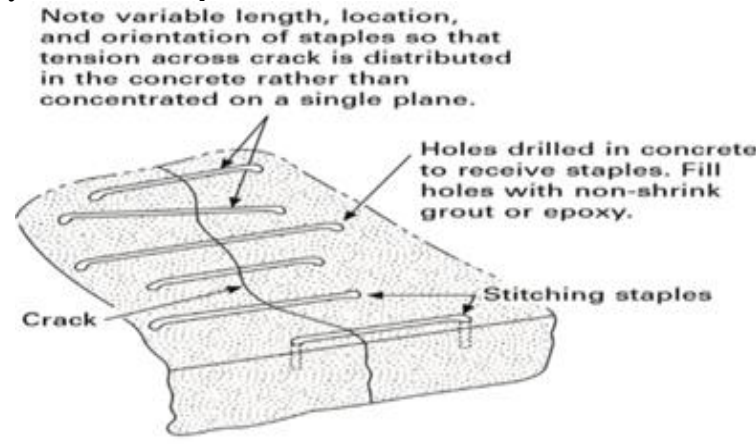

Figure 8: Repair of crack by stitching ${ }^{[18]}$

\subsection{Additional reinforcement}

Conventional reinforcement: The broken beams of the reinforced concrete bridge have been successfully repaired by reinforcement and bonding with epoxy resin [26] [27] [28]. This technique consists of sealing the crack and making holes that cut the plane of the crack at approximately $90^{\circ}$ (Figure 9).
Figure 9: Reinforcing bar orientation used to effect the repair ${ }^{[26]}$

Prestressing steel: Preload is generally the preferred solution when it is necessary to reinforce a large part of an element or when it is necessary to close the cracks (Figure 10). This technique uses ropes or tie rods to apply a compressive force. Adequate anchoring for steel prestressing should be ensured and care should be taken not to spread the problem to just another part of the structure. The effects of stress on stress within the facility must be carefully analyzed. In the case of undefined structures re-tightened with this method, the effects of the secondary moments and the reactions generated [29] [30] have to be taken into account.

\subsection{Drilling and plugging}

Drilling and inserting a crack is drilling the length of the crack and connecting it with a wrench (Figure 12). This technique is only applicable if the cracks run in fairly straight lines and are accessible at one end. This method is generally used to repair vertical cracks in retaining walls. A hole [typically $50-75 \mathrm{~mm}$ diameter] must be centered drilled at and after the crack.

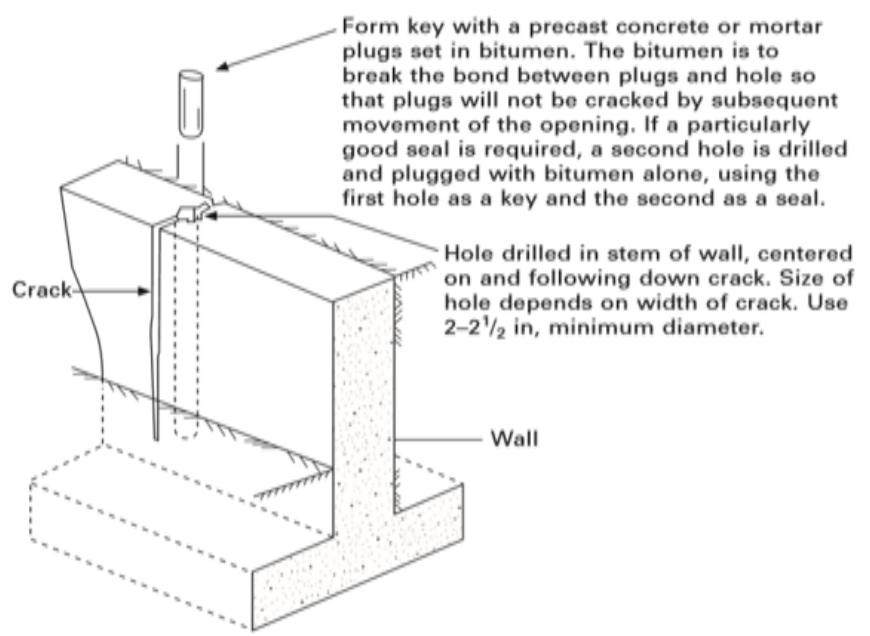

Figure 11: Repair by drilling and plugging ${ }^{[7]}$

The hole should be large enough to cut the entire length of the slot and provide enough repair material to structurally absorb the loads on the key. Therefore, the borehole must be cleaned, tightened and filled with mortar. The mortar prevents transverse movement of the concrete components near the crack. The key also reduces serious cracking and earth leakage behind a leaky wall. If water resistance is essential and structural load transfer is not the case, the hole should be filled with a low modulus elastic material rather than mortar. If the main effect is essential, the elastic

Volume 9 Issue 4, April 2020 www.ijsr.net 


\section{International Journal of Science and Research (IJSR) \\ ISSN: 2319-7064}

ResearchGate Impact Factor (2018): 0.28 | SJIF (2019): 7.583

material can be inserted into a second hole, with the first hole added.

\subsection{Gravity filling}

Low viscosity monomers and resins can be used to seal cracks with a surface width of 0.03 to $2 \mathrm{~mm}(0.001$ to 0.08 inch) by gravity fill [31]. Metacrylates, high molecular weight urethanes and some low viscosity epoxies have been used successfully. The lower the viscosity of monomers and resins, the thinner the cracks that can be filled. The process consists of cleaning the surface with air or water jets. Wet surfaces should dry for several days to get the best crack filler. The monomer or resin can be poured onto the surface and spread with a broom, roller or knife. The material must be worked back and forth through the slots for maximum filling as the monomer or resin slowly penetrates the crevices. Excess material must be removed from the surface to avoid smooth and shiny parts after curing. If surface friction is important, the sand must spread on the surface before the monomer or resin hardens. If the cracks contain significant amounts of sludge, moisture or other contaminants, the kit will not be able to fill them. Cleaning with water followed by a drying time can be effective in cleaning and preparing these cracks. The cores removed from the cracks can be used to evaluate the effectiveness of the filler. The penetration depth of the kit can be measured. Shear or tensile tests can be performed if the load is applied in a direction parallel to the repaired cracks (provided there is no steel reinforcing the core within or near the fracture area). With some polymers, the fracture crack occurs outside the repaired crack.

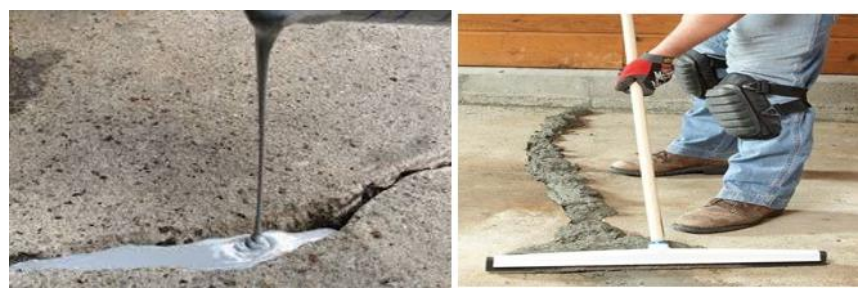

Figure 13: Gravity filling method of crack repairs

\subsection{Grouting}

Portland cement grouting: The large cracks, especially in gravity dams and thick concrete walls, can be repaired by filling with Portland cement mortar. This method is effective for stopping water leaks, but does not structurally connect cracked sections. The procedure is to clean the concrete along the crack; Install upright seats (mortar nozzles) over the crack at regular intervals to create a pressure-tight connection to the injector; Seal the gap between the seats with cement paint, sealant or mortar; Rinse the slot to clean and test the seal and then add the whole area. Depending on the width of the crack, the mortar mixes may contain cement and water or cement plus sand and water. However, the water-cement ratio should be kept as low as possible to maximize strength and minimize shrinkage. Water reducing agents or other additives can be used to improve the properties of the mortar. A manual injector can be used for small quantities; A pump is required for large quantities.
Maintain pressure for several minutes after filling the crack to ensure good penetration.

Chemical grouting: Chemical mortars are made up of solutions of two or more chemicals (such as urethanes, sodium silicates and acrylic homides) which together form a gel, a solid precipitate or a foam, unlike cement mortars, which consist of suspensions of solid particles in a liquid. Cracks in the concrete of only $0.05 \mathrm{~mm}$ (0.002 inches) were filled with chemical mortar. The merit of the chemical mortar include its applicability in humid environments (excessive humidity available), wide control limits of the gel time and the ability to be used in very fine breaks. The demerit are the high level of skill required for satisfactory use and the lack of strength.

\subsection{Dry-pack}

Dry-packing is the hand placement of a low water content mortar followed by tamping or ramming of the mortar into place, producing intimate contact between the mortar and the existing concrete ${ }^{[32]}$. Because of the low water-cement ratio of the material, there is little shrinkage, and the patch remains tight and can have good quality with respect to durability, strength, and water tightness. Dry-pack can be used for filling narrow slots cut for the repair of dormant cracks. The use of dry-pack is not advisable for filling or repairing active cracks. Before a crack is repaired by drypacking, the portion adjacent to the surface should be widened to a slot about 1 in. $(25 \mathrm{~mm})$ wide and $1 \mathrm{in} .(25 \mathrm{~mm})$ deep. The slot should be undercut so that the base width is slightly greater than the surface width. After the slot has been thoroughly cleaned and dried, a bond coat, consisting of cement slurry or equal quantities of cement and fine sand mixed with water to a fluid paste consistency, or an appropriate latex bonding compound ${ }^{[33]}$, should be applied. Placing of the dry-pack mortar should begin immediately. The mortar consists of one part cement, one to three parts sand passing a No. 16 (1.18mm) sieve, and just enough water so that the mortar will stick together when molded into a ball by hand. If the patch must match the color of the surrounding concrete, a blend of grey Portland cement and white Portland cement may be used. Normally, about onethird white cement is adequate, but the precise proportions can be determined only by trial. To minimize shrinkage in place, the mortar should stand for $1 / 2$ hour after mixing and then should be remixed prior to use. The mortar should be placed in layers about $3 / 8$ in. (10mm) thick. Each layer should be thoroughly compacted over the surface using a blunt stick or hammer, and each underlying layer should be scratched to facilitate bonding with the next layer. There need be no time delays between layers.

The mortar may be finished by laying the flat side of a hardwood piece against it and striking it several times with a hammer. Surface appearance may be improved by a few light strokes with a rag or sponge float. The repair should be cured by using either water or a curing compound. The simplest method of moist curing is to support a strip of folded wet burlap along the length of the crack 


\section{International Journal of Science and Research (IJSR) \\ ISSN: 2319-7064}

ResearchGate Impact Factor (2018): 0.28 | SJIF (2019): 7.583

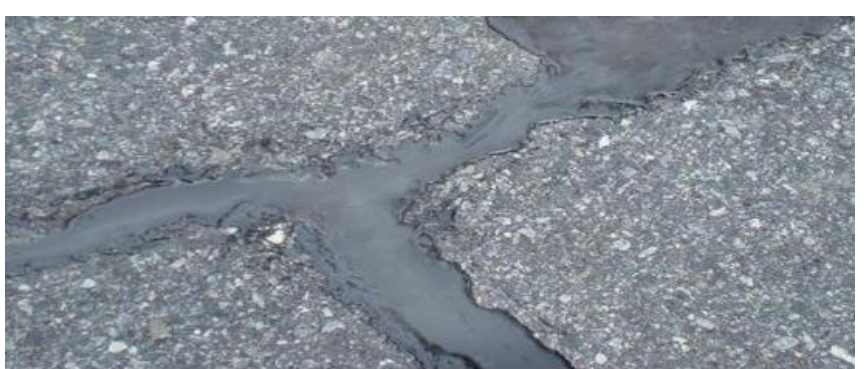

Figure14: Dry-pack method of crack repairs

\subsection{Crack arrest}

During the construction of solid concrete structures, cracks can occur due to surface cooling or other causes and can spread to new concrete during construction. Such cracks can be stopped by blocking the crack and spreading stress over a wider area [34]. While further concrete, a piece of membrane or steel grid can be placed over the crack. A semicircular tube can also be used above the crack (Fig. 6.13). The following is a description of the installation procedures for the semicircular pipes used in the construction of a solid concrete structure: (i) The semicircular pipe is made by dividing a $200 \mathrm{~mm}(8$ inch) pipe $16 \mathrm{~mm}$ guage pipe and forming a semicircular section with approximately a bent with $75 \mathrm{~mm}$ flange on each side; (ii) the area at the crack is cleaned; (iii) the tube is arranged in sections to remain centered in the slot; (iv) the sections are welded together; (v) the holes are drilled in the top part of the pipe to receive the connecting pipes; and (vi) after laying the connecting pipes, the installation is covered with concrete, which is placed concentrically on the pipe by hand. The installed connecting tubes are used to fill the crack later, partially or completely restoring structural continuity.

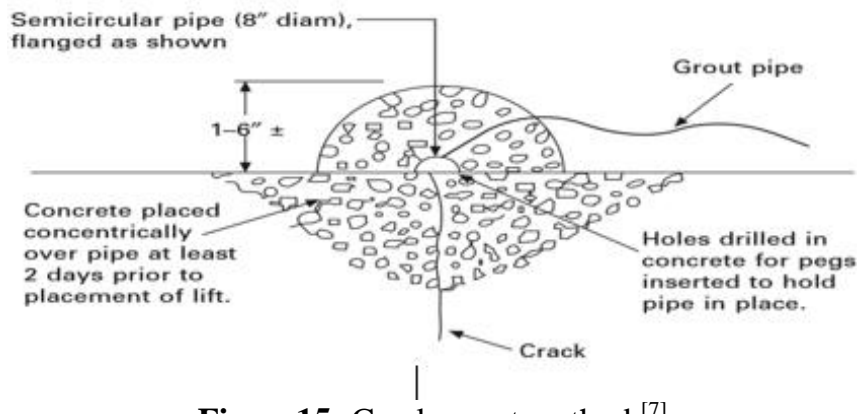

Figure15: Crack arrest method ${ }^{[7]}$

\subsection{Polymer Impregnation}

Monomer systems can be used to effectively repair some cracks. A monomer system is a liquid that consists of monomers that polymerize into a solid. Suitable monomers have different levels of volatility, toxicity, and flammability. They do not mix with water. They have a very low viscosity and penetrate dry concrete and fill cracks like water. The most widely used monomer for this is methyl methacrylate. The monomer systems used for impregnation contain a catalyst or an initiator plus the basic monomer (or a combination of monomers). They can also contain a crosslinking agent. When heated, the monomers adhere or polymerize, creating a strong, strong, and durable plastic that significantly improves some properties of concrete. When a cracked concrete surface dries, floods with the monomer, and polymerizes in place, some cracks are structurally filled and repaired. However, if the cracks contain moisture, the monomer does not penetrate the concrete at every crack surface, and therefore the repair is unsatisfactory. If a volatile monomer evaporates prior to polymerization, it is not effective. Polymer impregnation has not been used successfully to repair thin cracks. Polymer impregnation was mainly used to obtain more resistant and waterproof surfaces [35] [36]. Very broken beams were repaired by impregnation with polymers. The method includes drying the fracture, temporarily sealing it on a waterproof (monomer resistant) metal strip, impregnating the fractures with the monomer, and polymerizing the monomer. Large cavities or fracture areas in the compression zones can be filled with coarse and fine aggregate before they are flooded with monomer, which can be used to repair polymer concrete.

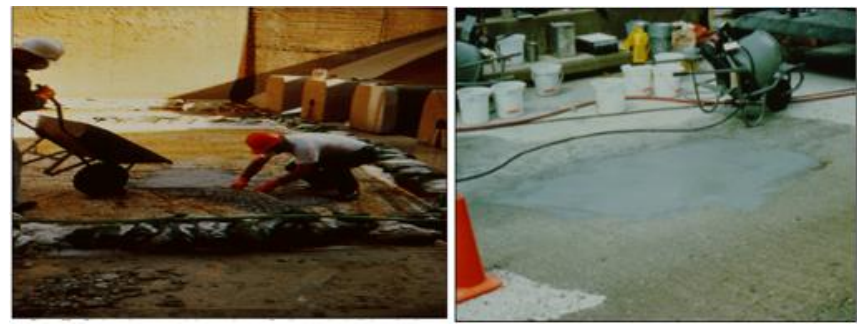

Figure16: Placing polymers in a repair area before and ater

\subsection{Overlay and Surface Treatments}

In the absence of significant movement through the cracks, it is possible to repair thin surface cracks in slabs and structural walkways with a glued bearing or a surface treatment. Untied coatings can be used to cover, but not necessarily repair, a panel. Coatings and surface treatments may be suitable for single event cracks and do not fully penetrate the sheet. These techniques are not suitable for repairing progressive cracking caused by reactive and Dcracking aggregates.

Flat panels under freezing conditions should not be repaired with a pad or surface treatment that provides a vapor barrier. A watertight barrier leads to condensation coming out of the substrate, causing critical saturation of the concrete and rapid disintegration during freeze-thaw cycles.

Surface Treatments: Low solids and low viscosity resin systems were used to seal concrete surfaces, including the treatment of very fine cracks. They are best suited for surfaces that are not subject to significant wear. Bridge decks and parking frame panels, as well as other interior panels, can be effectively treated after cracks have been treated by epoxy injection or by positioning and sealing. Materials such as urethane, epoxy, polyester and acrylic were applied in a thickness of 1 to $50 \mathrm{~mm}$ (0.04 to 2.0 inches) depending on the material and purpose of the treatment. Anti-slip aggregates are often mixed into the material or cleaned on the surface to improve traction.

Overlays: Thin cracks at rest can be repaired by applying a coating such as polymer, modified Portland cement mortar, or concrete, or by using silicon vapor concrete. Slabs with working slits can be covered if the joints are placed in the overlap directly above the working slits. A film thickness of

Volume 9 Issue 4, April 2020 www.ijsr.net 


\section{International Journal of Science and Research (IJSR) \\ ISSN: 2319-7064}

ResearchGate Impact Factor (2018): 0.28 | SJIF (2019): 7.583

only $30 \mathrm{~mm}$ (11/4 inches) has been successfully used in road bridge applications [37]. Suitable polymers include styrenebutadiene or acrylic latexes. The resin solids should have at least $15 \%$ by weight of Portland cement, with $20 \%$ generally optimal [38]

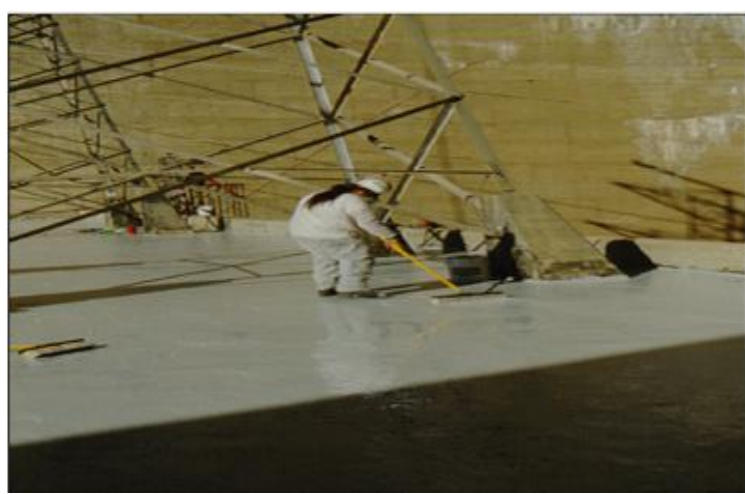

Figure 17: Overlay application with brooms, squeegees or heavy industrial grade paint roller

\subsection{Autogenous healing}

A natural crack repair process known as "autogenous healing" can take place in concrete in the presence of moisture and without stress [39]. It has a practical application for closing inactive cracks in a humid environment, for example in solid concrete structures. The hardening takes place through the continuous hydration of the cement and the carbonation of the calcium hydroxide in the cement paste by carbon dioxide, present in the air and in the ambient water. Calcium carbonate and calcium hydroxide crystals precipitate, accumulate and grow in cracks. The crystals tangle and twist, creating a mechanical bonding effect which is complemented by a chemical bond between the adjacent crystals and between the crystals and the surfaces of the paste and aggregate. As a result, part of the tensile strength of concrete is restored from the cracked part and the crack can be sealed. Healing does not take place when the tear is active and there is movement during the healing period. Also, curing does not occur if there is a positive water flow through the crack that dissolves and removes limescale unless the water flow is so slow that complete evaporation occurs on the exposed surface. Saturation of the crack and adjacent concrete with water during the healing process is important to develop significant strength. Immersion of the torn portion is desirable. Alternatively, water can collect on the concrete surface, so that the crack becomes saturated. Saturation should be continuous throughout the healing phase. A single cycle of drying and re-immersion drastically reduces the healing power. Healing should begin as soon as possible after the crack has occurred. Delayed healing results in less recovery from strength than an immediate correction.

\section{Conclusion}

The need to determine the causes of cracks in concrete structures is a necessary condition for repair. Choosing effective repair techniques should take into account the causes of the cracks, whether the cracks are active or inactive and whether repairs are needed. The criteria for selecting crack repair methods are based on the desired outcome of the repairs. Twelve methods of crack repair are presented, including techniques, advantages and disadvantages and their respective areas of application. When repairing cracks, it must be prevented before cracking. If there are cracks, corrective actions and methods are suggested. The following provides detailed conclusions from our research. Proper construction methods should be used during construction to prevent formation of cracks.

- However if there are any cracks, visual inspection should be done first.

- Cause of the cracks should be done with first before repairing.

- Evaluation of cracks can be done by different technique like crack compactor and ultrasonic testing.

- Epoxy injection can be used for narrow cracks (0.002 in $0.05 \mathrm{~mm})$.

- Stitching can be used across major cracks.

- In case of bridge girder, provision of pre-stressing steel is useful.

- In evaluating material causes of cracking, photographic examination is used.

\section{References}

[1] Nounu, G. and Z. Chaudhary, 1999. Reinforced Concrete Repairs in Beams. Construction and Building Materials, 13: 195-212.

[2] Kovács, T., 2000. Deterioration of Reinforced Concrete Repair Mortar Layers. Periodica Polytechnica Ser. Civ. Eng., 44: 197-206.

[3] Kenai, S. and Bahar, R.(2003). Evaluation and repair of Algiers new airport building, Cement and Concrete Composites, 25: 633-641.

[4] Mukherjee, A. and M. Joshi, 2000. Recent Advances in Repair and Rehabilitation of RCC Structures with Nonmetallic Fibers.

[5] Choppola, L. 2000. Concrete Durability and Repair Technology. ENCO Engineering and Concrete Spresiano (TV).

[6] Al-Dulaijan, S.U., M.M. Al-Zahrani, H. Saricimen, M. Maslehuddin, M. Shameem and T.A. Abbasi, 2002. Effect of rebar cleanliness and repair materials on reinforcement corrosion and flexural strength of repaired concrete beams. Cement and Concrete Composite, 24: 139-149.

[7] ACI Committee 224 1R-93 1998. Causes, Evaluation and Repair of Cracks in Concrete Structures. Concrete Repair Manua, 2nd Edn. Published jointly by ACI International, Building Research Establishment, Concrete Society and International Concrete Repair Institute in the year 2003, ISBN: 087031-105-0. Vol. 1. 1: 485-550.

[8] Cambel-Allen, D. and H. Roper, 1991. Concrete structures: Material, Maintenance and Repair. Concrete Design and Construction Series. 1st edn. New York: John Wiley and Sons pp: 58-101, 118120, 139-151, 243-285.

[9] Perkins, P.H., 1976. Concrete Structures: Repair, Waterproofing and Protection..London, ISBN: 085334 697. Applied Science Publishers LTD. 


\section{International Journal of Science and Research (IJSR) \\ ISSN: 2319-7064}

ResearchGate Impact Factor (2018): 0.28 | SJIF (2019): 7.583

[10] Macginley, T.J. and B.S. Choo, 1990. Reinforced Concrete, Design Theory and Example, 2nd Edn. London SE1 8HN, UK. E \& FN Spon, an imprint of Chapman and Hall.

[11] Vaysurd, M., P.H. Emmons and N.P. Mailvaganam, 2004. Concrete Repair Technology- A Revised Approach Is Needed. The Magazine of American Concrete Institute. Concrete International.Vol. 26 No. 1.

[12] Kum, W. and Tham, 1992. Durability of Concrete Structures. Continuing Educational Workshop on Rehabilitaton and Repair of Structures, IEB, Malaysia, 16th to 17 th April.

[13]ICRI Technical Guideline Committee-03733, 1996. Guide for Selecting and Specifying for Repair of Concrete Surfaces. Concrete Repair Manual, 2nd edn. Published jointly by ACI International, Building Research Establishment, Concrete Society and International Concrete Repair Institute in the year 2003. ISBN: 0-87031-105-0, Vol. 1, pp: 835-912

[14] Kenai, S. and Bahar, R.(2003). Evaluation and repair of Algiers new airport building, Cement and Concrete Composites, 25: 633-641.

[15]ICRI Technical Guideline Committe-03730, 1996. Guide for Surface Preparation for the Repair of Deteriorated Concrete Resulting from Reinforcing Steel Corrosion. Concrete Repair Manual, 2nd end. Published jointly by ACI International, Building Research Establishment, Concrete Society and International Concrete Repair Institute in the year 2003, ISBN: 087031-105-0, Vol. 1, pp: 916-921.

[16]Tan, H., 1992. A systematic Approach to Concrete Repair. Continuing Educational Workshop on Rehabilitation and Repair of Structures, IEB, Malaysia, 16th to 17th April.

[17] Allen, R.T.L., 1974. The repair of concrete structures. Cement and Concrete Association, London SWIW 0AQ.

[18] Johnson, S.M. (1965), Deterioration, Maintenance and Repair of Structures, McGraw-Hill, New York.

[19]ACI Committee Report 503R-93, Use of epoxy compounds with concrete, ACI Manual of Concrete, American Concrete Institute, Farmington Hills, MI.

[20]ASTM C881 / C881M, Standard Specification for Epoxy-Resin-Base Bonding Systems for Concrete, Annual Book of ASTM Standards, American society for Testing and Materials, West Conshohocken, PA.

[21] Adams R D and Wake W C (1984), Structural Adhesive Joints in Engineering, Elsevier, London and New York.

[22] Stratton, F. Wayne, and McCollom, Bruce F. (1974), Repair of Hollow or Softened Areas in Bridge Decks by Rebonding with Injected Epoxy Resin or Other Polymers, Report No. K-F-72-5, state Highway Commission of Kansas, Ei Donado, KS

[23] Smith, Barbara J. (1992), Epoxy injection of bridge deck delaminations, Transportation Research Record 1533, Transportation Research Board, National Research Council, Washington DC, 10-18.

[24] Smithson, Leland D. and Whiting, John E. (1992), Rebonding delaminated bridge deck overlays, Concrete Repair Digest, 3(3), June/July, 100-101.

[25] Hoskins, B.E., Fowler, D.W. and McCullough, B.F. (1991), An Evaluation of Repair Techniques Used for Uncontrolled Longitudinal Cracking and Failed
Longitudinal Joints, Research Report 920-4, Center for Transportation Research, The University of Texas at Austin.

[26] Stratton, F. Wayne; Alexander, Roger; and Nolting, William (1978), Cracked Structural Concrete Repair through Epoxy Injection and Rebar Insertion, Report No. FHWAKs-RD.78-3, Kansas Department of Transportation, Topeka, Ks, November.

[27] Stratton, F. Wayne (1980), Custom concrete drill helps repair shear cracks in bridge girders, Concrete International: Design and Construction, 2(9), September, 118-119.

[28] Stratton, F.W., Alexander, R. and Nolting, W. (1982), Development and Implementation of Concrete Girder Repair by Using Post-Reinforcement, Report No. FHWA-Ks-82-1, Kansas Department of Transportation, Topeka, Ks.

[29] Lin, T.Y. and Burns, Ned H. (1981), Design of Prestressed Concrete Structures, 3rd edn, Wiley, New York.

[30] Nilson, Arthur H. (1987), Design of Prestressed Concrete, 2nd edn, Wiley, New York.

[31] Rodler, D.J., Whitney, D.P., Fowler, D.W. and Wheat, D.L. (1989), Repair of cracked concrete with high molecular weight methacrylates, Polymers in Concrete: Advances and Applications, sP-116, American Concrete Institute, Farmington Hills, MI, 113-127.

[32] Us Bureau of Reclamation (1975), Concrete Manual, 8th edn, Denver, CO.

[33] ASTM C1059 / C1059M, Standard Specification for Latex Agents for Bonding Fresh To Hardened Concrete, Annual Book of ASTM Standards, American society for Testing and Materials, West Conshohocken, PA.

[34] Us Army Corps of Engineers (USACE) (1995), Maintenance and Repair of Concrete and Concrete Structures, Engineer manual 1110-2-2002, Washington DC.

[35] Hallin, J.P. (1978), Field evaluation of polymer impregnation of new bridge deck surfaces, Polymers in Concrete, sP-58, American Concrete Institute, Farmington Hills, WI, 267-280.

[36] Webster, R.P., Fowler, D.W. and Paul, D.R. (1978), Bridge deck impregnation in Texas, Polymers in Concrete, sP-58, American Concrete Institute, Farmington Hills, MI, 249-265.

[37] National Cooperative Highway Research Program 1970), Synthesis 57, Concrete Bridge Deck Durability, Washington DC.

[38] Clear, K.C. and Chollar, B.H. (1978), StyreneButadiene Latex Modifiers for Bridge Deck Overlay Concrete, Report No. FHWA-RD-78-35, Federal Highway Administration, Washington DC.

[39] Lauer, Kenneth R., and slate, Floyd O. (1956), Autogenous healing of cement paste, ACI JOURNAL, Proceedings, 27(10), June, 1083-1098.

[40]Broms, B. B., and Lutz, L. A., 1965, "Effects of Arrangement of Reinforcement on Crack Width and Spacing of Reinforced Concrete Members," ACI JOURNAL, Proceedings V. 62, No. 11, Nov., pp. 1395 1410.

[41] Gergely, P., and Lutz, L. A., 1968, "Maximum Crack Width in Reinforced Concrete Members, "Causes,

\section{Volume 9 Issue 4, April 2020}




\section{International Journal of Science and Research (IJSR) \\ ISSN: 2319-7064}

ResearchGate Impact Factor (2018): 0.28 | SJIF (2019): 7.583

Mechanism, and Control of Cracking in Concrete, SP20, American Concrete Institute, Farmington Hills, Mich., pp. 87-117.

[42] Illston, J. M., and Stevens, R. F., 1972, "Long-Term Cracking in Reinforced Concrete Beams, "Proceedings, Institution of Civil Engineers (London), Part 2, V. 53, pp. 445-459.

[43] Abeles, P. W.; Brown, E. L., II; and Morrow, J. W., 1968,"Development and Distribution of Cracks in Rectangular Prestressed Beams During Static and Fatigue Loading," Journal, Prestressed Concrete Institute, V. 13, No. 5, Oct., pp. 36-51

[44]Bennett, E. W., and Dave, N. J., 1969, "Test Performances and Design of Beams with Limited Prestress," The Structural Engineer (London), V. 47, No. 12, Dec., pp. 487-496.Bentur, A.; Diamond, S.; and Berke, N. S., 1997, Steel Corrosion in Concrete, E\&FN Spon, London, $201 \mathrm{pp}$.

[45]Rehm, G., and Eligehausen, R., 1977, “Lapped Splices of Deformed Bars Under Repeated Loadings (Ubergreifungs-tosse von Rippenstahlen unter nicht ruhender Belastung)," Beton und Stahlbeton (Berlin), No. 7, pp. 170-174.

[46] Holmberg, A., 1973, "Crack Width Prediction and Minimum Reinforcement for Crack Control," Dansk Slesab for Bygn-ingsstatitik (Copenhagen), V. 44, No. 2, June, pp. 41-50.

Volume 9 Issue 4, April 2020 www.ijsr.net 